\section{DE LOS DERECHOS SOCIALES SOBRE LIBERTAD E IGUALDAD A LA DEFINICIÓN DE LOS DERECHOS CIVILES Y POLÍTICOS DESPUÉS DE LA INDEPENDENCIA*}

\section{Jacqueline Blanco Blanco**}

Fecha de Recepción: 13 de Octubre de 2010

Fecha de Aceptación: 19 de noviembre de 2010 Artículo Reflexión.

\section{Resumen}

Las denominadas minorías étnicas en Colombia corresponden a un sector de la población al que los beneficios del Estado liberal y la democracia llegaron con absoluta lentitud. La concepción de los derechos a la igualdad y a

* Este artículo es resultado parcial de la investigación denominada "Evolución constitucional de los derechos sociales, civiles y políticos a favor de las minorías étnicas y de género en Colombia"; forma parte del macroproyecto "Evolución de los derechos constitucionales en el bicentenario constitucional (1810-2010)", en el marco de la conmemoración del Bicentenario de la Independencia de Colombia. Corresponde a un producto académico de la línea "Historia del Derecho Administrativo en Colombia", del grupo "Derecho Público", categoría B - COLCIENCIAS, de la Facultad de Derecho de la Universidad Militar Nueva Granada. Parte del texto fue presentado como ponencia en la Facultad de Derecho de la Universidad Icesi de Cali, el 5 de noviembre de 2009, como documento de entrada de la autora al Instituto Colombiano de Historia del Derecho, fue publicado en el 2010 en un número especial de la revista "Precedente", de la misma Universidad.

** Licenciada en Ciencias Sociales de la Universidad Libre, Especialista en Filosofía del Derecho y Teoría Jurídica de la misma Universidad, Magíster en Historia de la Universidad Industrial de Santander, Doctoranda en Sociología Jurídica e Instituciones Políticas de la Universidad Externado de Colombia; docente de pregrado y postgrado en programas de Derecho; investigadora del Centro de Investigaciones de la Facultad de Derecho de la Universidad Militar Nueva Granada; directora de la línea de investigación Historia del Derecho Administrativo en Colombia. Miembro del Instituto Latinoamericano de Historia del Derecho ILHAD y Secretaria del Instituto Colombiano de Historia del Derecho ICHD. jacbla201@yahoo.es. libertad, ciertamente concebidos como fundamentales e inherentes al ser humano, no fueron igualmente interpretados por los hombres libres y de "bien" que habitaron y pensaron la república; como una prolongación del coloniaje, la esclavitud continuó siendo una institución mientras la manumisión no logró ser a plenitud un sinónimo de libertad en razón a los condicionamientos políticos, sociales y económicos que le asistieron.

La igualdad fue el principio que dio lugar a la libertad, pero tanto la igualdad como libertad propiciaron el acceso a los demás derechos, para el caso, ni los negros ni los naturales fueron iguales a los blancos, la libertad fue restringida, y los demás derechos civiles y políticos inevitablemente esquivos.

\section{Palabras clave}

Libertad, igualdad, derechos, garantías, participación.

\section{THE SOCIAL RIGHTS ON FREEDOM AND EQUALITY TO THE DEFINITION OF THE CIVIL RIGHTS AND POLITICAL AFTER INDEPENDENCE}

\begin{abstract}
The called ethnic minorities in Colombia relate to a sector of the population to which the benefits of liberal State and democracy arrived with absolute slowly. The design of the rights to equality and freedom, certainly designed as fundamental and inherent to the human being, were not equally interpreted by the free men and "good" that inhabited and thought the republic; as an extension of colonialism, slavery continued to be an institution while the manumission failed to be a fullness a synonym for freedom in reason to the political, social and economic you attended.
\end{abstract}

The equality was the principle that led to the freedom, but both equality as freedom led to the 
access to the other rights, for the case, neither blacks nor the natural were equal to the whites, the freedom was restricted, and the other civil rights and political inevitably elusive.

\section{Key words}

Freedom, equity, guarantees, participation, rights.

\section{INTRODUCCIÓN}

La historia de los derechos de los colombianos debe estudiarse a partir de tres variables específicas: la económica, la política y la social; el orden obedece al nivel de jerarquía que determina la adopción, adaptación o transformación de cada uno de esos derechos.

El factor económico ha permitido avanzar hacia la puesta en operatividad de una serie de principios pero ha restringido su plenitud, de acuerdo con los niveles de afectación que pueda provocar, en algunas condiciones conexas, la generalización de ciertos derechos puede constituir en un momento determinado, amenazas a los grupos económicos que sostienen el poder político, y aquí entra la segunda variable que por mantener una estrecha relación con la primera, admite la vinculación o no de los derechos y su posterior definición como garantías. Por último, la condición social representada en todos los sujetos a que beneficia o no la decisión jurídica, ejerce presión a las dos anteriores y obliga a la toma de decisiones a favor del colectivo.

"De los derechos sociales sobre libertad e igualdad a la definición de los derechos civiles y políticos después de la independencia", es un texto que pretende acercarse a la historia de los derechos de los colombianos en los tiempos de la transición de la colonia a la república, partiendo del supuesto que en el reconocimiento a la igualdad y la libertad, como principios estructurales invocados en los discursos políticos de los actores centrales del conflicto interno de la década de 1810 a 1820, reposaba la naturaleza de los otros derechos, bien fueran de carácter civil o político. Es por esto que el problema de investigación remite a la necesidad de observar dicho proceso a partir de una innegable trayectoria de exclusión, en su momento pertinente y propicia a los intereses económicos y políticos del grupo en el poder.

Para apreciar la afirmación sobre el carácter excluyente de que fueron sujetos los esclavos en materia de derechos, en el artículo se hace un llamado al tema de la manumisión como medida jurídica que propendió por la libertad de estos, pero tal decisión se entiende desde una concepción política y económica que restringió la posibilidad de la conformación de un cuerpo de nación consolidado, donde las garantías constitucionales fueran realmente operables.

Entre las fuentes más importantes que se tuvieron en cuenta para el desarrollo de esta propuesta se encuentran los fondos documentales de carácter público como los contenidos en el Archivo Histórico General de la Nación, ubicado en Bogotá; las memorias -como las de don Félix de Restrepo, don José María Samper, don Florentino González o don José Hilario López; algunas compilaciones de discursos, cartas y actas de congresos; periódicos, semanarios y gacetas de la época, dispuestas en la hemeroteca de la Biblioteca Luis Ángel Arango; las normas y constituciones del período seleccionado; algunas novelas como literatura que aporta gran belleza y naturalidad al texto; y algunos trabajos de historiadores nacionales y de los llamados "colombianistas", que se han dedicado con seriedad a conocer este período.

Al finalizar este artículo el lector se asomará a una versión diferente de la Independencia de Colombia, porque encontrará que pese a los ingentes esfuerzos sociales -más que políticosa lo largo de doscientos años el proceso ha quedado pendiente desde sus orígenes, deducción que se deja a su amable consideración y ponderación. 


\section{DE LOS DERECHOS SOCIALES SOBRE LIBERTAD E IGUALDAD A LA DEFINICIÓN DE LOS DERECHOS CIVILES Y POLÍTICOS DESPUES DE LA INDEPENDENCIA}

Uno de los documentos revolucionarios de mayor importancia para la historia política nacional es el "Memorial de Agravios". A través de el se logró expresar de manera oficial y pública el sentimiento de exclusión de que eran sujetos los nativos americanos; la expresión "nativo americano" a que se refiere el "Memorial" no generaliza la problemática social del pueblo neogranadino; más bien, específica las necesidades e intereses de un pequeño sector correspondiente al grupo de americanos residentes en Nueva Granada. Contrario a lo estimado por muchos historiadores, el "Memorial de Agravios" constituye una pieza literaria de rechazo sentido por los criollos americanos y provocado por sus pares europeos, y deja por fuera a la mayoría -no criolla y no blanca- altamente afectada por el coloniaje español.

"Las Américas, señor, no están compuestas de extranjeros a la nación española. Somos hijos, somos descendientes de los que han derramado su sangre por adquirir estos nuevos dominios a la Corona de España [...]";

la expresión señala el distanciamiento social y étnico que los criollos trasplantaron de los europeos a sus propios connacionales al excluir de ese sentimiento a quienes no eran hijos y descendientes de los españoles, sino de los naturales americanos y de los negros africanos. De acuerdo con la historiadora Margarita Garrido ${ }^{2}$ el desconocimiento que don Camilo Torres hace de los demás sectores sociales (afros e indígenas), tiene que ver con la afectación económica causada por una decisión jurídica real

CASTRO, José Félix (Comp.). El Memorial de Agravios. Publicitaria. Bogotá. 1991. p. 11-12.

2 GARRIDO, Margarita. Reclamos y representaciones: Variaciones sobre la politica en la Nueva Granada. 1780 1815. Banco de la República. Bogotá. 1993. p. 69. de conceder la libertad a los esclavos, o mano de obra, y la amenaza que representaba elevarlos a una condición de igualdad especialmente en el manejo de lo político; en otras líneas, el profesor Oscar Mejía reconoce esta misma interpretación al precisar que los sectores sociales de mayor vulnerabilidad en la Nueva Granada fueron relegados de un proyecto nacional que les afectara favorablemente:

"la Independencia se presenta como una lucha entre las clases dirigentes criollas y la alta burguesía española, pero sin que aquella logre comprometer a las clases populares -indígenas, negros, mestizos, descamisados- al no contemplar en el proyecto inicial ninguna reivindicación a favor de éstas"”.

Liberte, Igalite et Fraternite, la famosa consigna que fue trasladada de Francia a América. Bajo la promesa de alcanzar los anhelados principios de libertad e igualdad los gestores de la independencia convocaron y movieron la participación de todos los granadinos, con los discursos libertarios prometieron un Estado sin opresión y cargado de oportunidades y garantías $^{4}$, la igualdad operó como una condición de relevancia a los individuos gracias a la cual se alcanzaban otros derechos como la libertad, la participación, y el beneficio común a que podían acceder los nuevos ciudadanos.

Que la intención social de los criollos de proteger a los más débiles no hubiera superado las acaloradas manifestaciones libertarias

3 MEJÍA QUINTANA, Oscar, et al. Cultura y Democracia en América Latina. Elementos para una reinterpretación de la cultura y la historia latinoamericana. M\&T. Bogotá. 1992. p. 209.

4 "Garantizar los derechos significa reconocimiento de los mismos, por lo que se procedió a su positivización en los textos constitucionales. La palabra garantía hace referencia a las constancia por escrito que se hacía de los derechos que ene ese entonces aquellos fueron designados bajo la expresión: derechos individuales o más genéricamente derechos del hombre y el ciudadano [...]". En: ESPINOZA DE LOS MONTEROS, Javier, et al. La noción de los Derechos en la historia del constitucionalismo mexicano. Suprema Corte de Justicia de la Nación. México. 2009. p. 53. 
contenidas en los discursos, no constituyó razón para no haber emprendido la modernización del Estado de acuerdo con la vigencia internacional, por lo menos en cuanto a lo consignado en las constituciones provinciales. La adopción de un sistema liberal y la inclusión de una serie de libertades individuales fue tomada de naciones como Norte América, Francia o Inglaterra, convirtiéndose éstas en el norte del proyecto para el nuevo pacto social: "Imitemos la conducta de los norteamericanos, sigamos los pasos de este pueblo de filósofos, y entonces seremos tan felices como ellos"5; igualmente, la novedad de vincular derechos relativos a la igualdad y a la libertad en las constituciones provinciales, funcionó como una inserción del texto original de los Derechos del Hombre y del Ciudadano.

Otro documento de decisiva importancia para la consolidación de los derechos de los habitantes de la Nueva Granada fue redactado por el "Libertador" Simón Bolívar y presentado públicamente el 15 de febrero de 1819 durante la instalación del Congreso de Angostura. En la interpretación que el líder político más importante del momento hace de la libertad, la noción política es altamente privilegiada:

"Un pueblo pervertido, si alcanza su libertad, muy pronto vuelve a perderla; porque en vano se esforzarán en mostrarle que la felicidad consiste en la práctica de la virtud; que el imperio de las leyes es más poderoso que el de los tiranos, porque son más inflexibles, y todo debe someterse a su benéfico rigor; que las buenas costumbres, y no la fuerza, son las columnas de las leyes; que el ejercicio de la justicia es el ejercicio de la libertad".

Convencido de la necesidad de preparar política y socialmente a quienes llama los "débiles

5 Carta de Camilo Torres al Oidor de Quito, Don Ignacio Tenorio. En: CASTRO, José Félix. Ob. Cit. p. 23.

6 Discurso pronunciado por Simón Bolívar el 15 de febrero de 1819, durante la instalación del Congreso de angostura. Disponible en: www.cervantesvirtual. com ciudadanos", Bolívar advierte que la libertad no puede concederse de manera inmediata y general; así las cosas, el estado de opresión causado por varios siglos de coloniaje y que había impedido elevar a la condición y al tratamiento se seres humanos en igualdad de condiciones a todos los granadinos, se proyectaba como una limitante para que el nuevo Estado definiera una política social de mayor impacto y declarara por fin la existencia de un cuerpo de nación en igualdad de condiciones:

"[...] La libertad, dice Rousseau, es un alimento suculento, pero de difícil digestión. Nuestros débiles ciudadanos tendrán que enrobustecer su espiritu mucho antes que logren digerir el saludable nutritivo de la libertad. Entumidos sus miembros por las cadenas, debilitadas, su vista en las sombras de las mazmorras, y aniquilados por las pestilencias serviles, ¿serán capaces de marchar con pasos firmes hacia el augusto templo de la libertad? ¿Serán capaces de admirar de cerca sus espléndidos rayos y respirar sin opresión el éter puro que alli reina? Meditad bien vuestra elección, legisladores. [...]"”.

Las limitaciones al ejercicio de la igualdad y de la libertad como condición social de los hombres, provenían de un estado de esclavitud institucionalizado por más de tres siglos; la rápida adopción de un sistema democrático y liberal no fue del todo posible en la medida que su generalización ponía en riesgo el aparato de poder heredado de los españoles a los criollos, nuevos gobernantes. Tal como lo afirma José Ramón Narváez ${ }^{8}$ la ciudadanía fue la fórmula mágica para la conformación de los nuevos Estados con gobernados plenos en garantías y derechos, pero la esclavitud que era objeto de permanente recriminaciones fue favorecida jurídicamente durante décadas, mientras la libertad debía esperar en un Estado que se definía como liberal: "[...] Los Estados modernos

Ibídem.

8 NARVÁEZ HERNÁNDEZ, José Ramón. Historia social del Derecho y la Justicia. Editorial Porrúa. México. 2007. p. 36. 
nacieron hipócritas: democráticos, pero solo a veces, libres pero no tanto".

\section{DE LOS DERECHOS SOCIALES A LOS DERECHOS CIVILES Y POLÍTICOS}

El historiador Thomas Marshall ${ }^{10}$ ha sostenido que los derechos civiles, sociales y políticos son componentes fundamentales del concepto moderno de ciudadanía y que ésta, a su vez, conlleva a la igualdad social dentro del proceso evolutivo de la sociedad que les permite a los individuos acceder a los derechos tanto civiles como políticos. Marshall ha definido como derechos civiles a los derechos necesarios para la libertad individual como la propiedad privada o la autonomía de negociación; como derechos políticos a los relativos a la participación en el poder político; y, como derechos sociales a los que tienen que ver con la seguridad, la educación y el bienestar económico.

La gran paradoja de Marshall se encuentra en la tendencia a la igualdad propia de un sistema democrático que busca la reivindicación de estos tres derechos, frente a la desigualdad que genera un sistema de mercado con tendencia capitalista, propia del S. XIX, que se orienta a la subordinación, minimiza los criterios de justicia social y afecta la protección de los derechos sociales. El capitalismo asegura la libertad y la individualidad pero establece una dependencia entre estos y los medios económicos que ejercen mayor respaldo en su sostenimiento.

La teoría propuesta por Marshall ofrece gran utilidad a la visión que se expone en el presente trabajo por cuanto se admite que la garantía de los derechos sociales, civiles y políticos, ha sido siempre selectiva, resultado de la correlación entre el aparato jurídico-político y el modelo económico en vigencia.

$9 \quad$ Ibíd. p. 42.

10 MARSHALL, Thomas. El concepto de ciudadanía. En: ESPINOZA DE LOS MONTEROS, et al. Ob. Cit. p. xix.
En materia, este texto privilegia el derecho a la igualdad por considerar que de ella se desprende la posibilidad de acceder a los demás derechos que le permitan equipararse al resto de la sociedad en cuanto a los beneficios propios de una Estado liberal. En Colombia, la igualdad condicionó a la libertad, pero la libertad condicionó el acceso a la participación, la representación y el reconocimiento individual de quienes no eran "blancos" o "criollos".

"La libertad, Sancho, es uno de los más preciosos dones que a los hombres dieron los cielos; con ella no pueden igualarse los tesoros que encierra $\underline{\text { la }}$ tierra ni el mar encubre; por la libertad así como por la honra se puede y debe aventurar la vida, $y$, por el contrario, el cautiverio es el mayor mal que puede venir a los hombres [...]" ${ }^{\prime 11}$.

De la libertad proclamada por Cervantes en su obra, a finales del siglo XVI, a la libertad conceptuada y aplicada en América casi dos siglos después, se revelan elementos de carácter muy superior al sentido pragmático con el cual se le trató en el nuevo mundo.

Aquél "precioso don" por el cual se debe aventurar la propia vida, como le aconseja don Quijote a su escudero, tardó varios años en hacerse realidad en la Nueva Granada. Las primeras menciones formales acerca de la libertad como derecho se hicieron en las constituciones provinciales sancionadas con posterioridad al 20 de julio de 1810; en ellas se entendía como "la facultad que el hombre tiene de hacer todo lo que no sea daño de tercero, o en perjuicio de la sociedad"12, y en mención constitucional fue claramente consignada en lo que tiene que ver con la libertad de

11 DE CERVANTES SAAVEDRA, Miguel. Don Quijote de la Mancha. Parte II. Capítulo LVIII. Disponible en: books.google.com.co

12 "Constitución de Antioquia, 1812. Artículo 2". En: POMBO, Miguel Antonio, et al. Constituciones de Colombia. T.I. Biblioteca Banco Popular. Vol. 127. Bogotá. 1986. 
expresión, la libertad de imprenta ${ }^{13}$, la libertad de autogobierno y soberanía ${ }^{14}$, la libertad para disfrutar de la propiedad privada, la libertad de participación o representación ${ }^{15}$, la libertad de comercio $^{16}$; o la libertad económica ${ }^{17}$.

La libertad que alcanzó naturaleza constitucional y constituyó uno de los grandes logros de la independencia, estuvo mayormente referida a un tipo de libertad pragmática, más del orden inmediatamente necesario para la convivencia; sin embargo, la libertad como condición social fue objeto de prolongadas discusiones en las que mediaron intereses individuales especialmente de carácter económico, que de paso afectaría otro de los derechos conquistados como era el derecho a la propiedad privada:

"El liberalismo nace con ciertas premisas, libertad solo dentro de ciertos parámetros, obviamente, el económico: Laissez faire, laissez passer; en principio la libertad que se busca es la de las mercancías no la de los hombres, o si acaso la de estos como mercancias, es por eso que la esclavitud en principio no era una institución que se buscó eliminar, es más, solo mutó, cambió de nombre [...]"18.

\section{LIBERTAD E IGUALDAD COMO PRINCIOS FUNDAMENTALES}

Las primeras decisiones legales a favor de la libertad quedaron consignadas en las constituciones provinciales, pero sus primeras menciones fueron una adaptación de los

13 NARIÑO, Antonio. "Pluris nubius". En: La Bagatela. Santa Fe. Domingo 2 de diciembre de 1811.

14 Art. 1 de la Constitución de 1821. En: POMBO, Miguel Antonio, et al. Ob. Cit.

15 "Continúan las reflexiones sobre nuestro Estado". En: Argos de la Nueva Granada. Santa fe, 29 de octubre de 1810. p. 28.

16 EL CONSTITUCIONAL. Bogotá, mayo 27 de 1821

17 Argos de la Nueva Granada. Santa fe, 8 de octubre de 1810. p. 18.

18 NARVÁEZ HERNÁNDEZ, José Ramón. Historia social del derecho y la justicia. Editorial Porrúa. México. 2007. p. 35.
"Derechos del Hombre y del Ciudadano" expuestos en 1789.

La libertad entendida como el "estado o condición de quien no es esclavo" 19 cobró relevancia a partir de la Ley de manumisión expedida el 20 de abril de 1814 en la provincia de Antioquia, pero dos años después, la libertad quedó sujeta a algunas determinaciones pertinentes para el momento político, a partir de entonces dependió de una y otra razón que buscó modificar, limitar o aplazar la libertad lograda; lo pragmático de la decisión fue sobrepuesto al espíritu social que se buscaba. En 1816, Bolívar dictó un decreto concediendo la libertad a los esclavos que se vincularan al ejército libertador llamando a todos los hombres que estuvieran entre los 14 y 60 años ${ }^{20}$, para 1820 ratificó esta decisión cuando le escribió al general Santander:

"Pedirá Ud. a las provincias de Antioquia, Chocó y Popayán, 3000 esclavos a las dos primeras y 2000 a la última, que sean solteros todos, si es posible. Se les ofrecerá la libertad desde el momento que salgan de su país, $y$ dos años después de haber entrado a servir, se les dará su licencia absoluta para que gocen de su plena libertad"21.

Con el Decreto de enero 11 de 1820, expedido por el Congreso Constituyente, se emprendieron los primeros proyectos sociales que complementaban el derecho a la libertad; se trataba de un efectivo trabajo de formación y educación que les permitiera la vinculación de los esclavizados al resto del colectivo social, para ello se dispuso:

"Promover activamente la primera civilización de los esclavos por medio de diversas instituciones, enseñando a leer y a escribir a los niños, dando a todos en general alguna idea de los saberes sociales,

19 DICCIONARIO DE LA REAL ACADEMIA ESPAÑOLA. Vigésima segunda edición. 2001.

20 Crónica de Caracas No.17. Marzo-Abril de 1954.

21 "E1 General Bolívar llama a las armas a 5000 esclavos y les ofrece la libertad. 1820". Disponible en: www. negrosyesclavos.archivogeneral.gov.co. 
inspirándoles amor al trabajo y a las virtudes públicas y haciendo depender de ellas mismas la más o menos pronta posesión de su libertad"22.

Por Ley del 21 de julio de 1821 el Congreso otorgó la libertad a los hijos de las esclavas que nacieran desde el día su publicación, e igualmente abolió el tráfico y comercio de los mismos, y ordenó, a los propietarios de esclavos, educar, vestir y alimentar a sus esclavizados durante los primero diez y ocho años de su vida; a cambio, recibirían de estos su actividad física como aporte ${ }^{23}$.

Las instrucciones sobre manumisión se fueron elaborando y precisando cada vez; sin embargo, no hubo ninguna transformación de fondo a lo ya convenido en 1821. Siguiendo lo indicado por la Ley, los primeros libertos en tiempos de la república alcanzarían este estado en el año de 1839 , pero no se debe olvidar que en 1814 se había establecido la edad de diez y seis años para manumitirse, que tal garantía se mantenía en vigencia, y que dicho tiempo se cumpliría en 1830. En el Archivo General de la Nación reposan varios documentos en los cuales el Síndico General Protector de Esclavos ${ }^{24}$, luego de 1821, iniciaba una acción judicial como apoderado

22 Decreto 22 de enero de 1820. Artículo 3. Disponible en: www.negrosyesclavos.archivogeneral.gov.co.

23 Disponible en: www.negrosyesclavos.archivogeneral. gov.co

24 La figura del Síndico Procurador Defensor de Esclavos no corresponde a la república, tiempos antes es mencionada en un documento real conocido como el "Código Negro", expedido por Carlos III en el año de 1789, y adaptado del Código Francés de 1685. El documento establece la educación, el trato y ocupación que se le debía dar a los esclavos negros en las Indias, para lograr una relación más humanitaria y que evitara el cimarronismo. Señala como tarea del Procurador Síndico, en su calidad de Protector de Esclavos, la indicación de la cantidad y cualidad de los alimentos y vestuario que se les proporcionaba a los esclavos por sus amos; la participación en la formación y determinación en el proceso de imposición de penas a los esclavos delincuentes; la visita y reconocimiento del estado en que se encontraban los esclavos en las diferentes haciendas, además de la presentación del de un esclavizado que reclamaba su libertad en razón a lo logrado en la Ley de $1814^{25}$; en documento similar se aprecia que, incluso la compra de la libertad de un esclavo a su amo no surtía efecto, siempre que éste se encontrara beneficiado por la Ley de manumisión:

"El Procurador General, protector de esclavos intercede a favor de la liberta Matías quien solicita a su antigua ama, Joaquina Escudero, le devuelva el dinero con el que pagó por su libertad, por haber nacido bajo la ley de manumisión" ${ }^{\text {"26. }}$

Las líneas arriba anotadas sobre cómo los intereses particulares determinaron la modificación de los contenidos de la Ley de manumisión y las implicaciones sobre el derecho a la libertad, se logran corroborar frente a decisiones como la tomada en el año de 1839 durante el gobierno de Presidente José Ignacio de Márquez, quien expidió una Ley para precisar lo dicho en 1821, llamada Ley de "aprendizaje". En ella establecía como condición el cumplimiento del Artículo 2 de la Ley de 21 de julio de 1821 que demandaba la "enseñanza" que debían recibir los esclavos como previo requisito para entrar al goce pleno de la libertad. Como el tema de la educación no había quedado muy claro y ésta no fue distinta a una formación religiosa, el gobierno de Márquez estimó que los esclavos estaban impreparados para vincularse provechosamente a la sociedad y que su condición de sujeción debía prolongarse por siete años más, o sea hasta los veinticinco. La Ley de Aprendizaje retrazó la manumisión por siete años, pero es preciso recordar que el Presidente Márquez había llegado al poder como miembro del

informe respectivo. En: "Código Negro". Disponible en: www.negrosyesclavos.archivogeneral.gov.co.

25 ARCHIVO HISTÓRICO DE ANTIOQUIA (AHA). Índice 1739. No. de orden 00404. Fondo: Colonia. Grupo: Negros y Esclavos. Serie: Documentos Históricos. Volumen: 4. Legajo: 38. Antioquia, 1824.

26 AHA. Indicie 1741. No. orden 00406. Fondo: Colonia. Grupo: Negros y esclavos. Sección: Antioquia. Serie: Documentos Históricos. Volumen 8. Legajo: 38. Folios: 525-532. 
partido conservador que se empeñaba a todas luces en proteger el sistema económico fundado en la agricultura, la minería y por supuesto, en la mano de obra esclava.

Las diferentes disposiciones jurídicas que versaron sobre libertad de esclavos no tuvieron la fuerza suficiente para provocar reacciones sociales igualmente propicias a este fin. La añeja cultura de la alteridad vista como "pecaminosa" e "indecente" y promulgada por la iglesia y la sociedad "blanca", señalaron un camino bastante definido que complicó la unidad nacional y por el contrario produjo el rechazo para aceptar la heterogeneidad a que daba lugar la coexistencia de diversos sectores sociales; de ahí que la política de inserción tendiera a una proceso "asimilacionista" donde el negro y el indio debían "aprender" la cultura de los blancos y ser como ellos para acceder al reconocimiento bajo una condición de igualdad que exigía la homogeneidad como categoría para su inclusión. Una de las partes que reaccionó con mayor prontitud y rechazo fue la de los esclavistas quienes no concebían que su antiguo esclavo -sujeto y objeto de su dominación- fuera ahora su igual, con la misma participación, y con un nivel de garantías y beneficios compartidos en equidad. Acerca de esta manifestación de resistencia el Senador Joaquín Mosquera, un reconocido miembro de la política y proveniente de una distinguida familia payanesa que soportaba su riqueza en la minería y por ende en la explotación de la mano de obra esclava, confirmaba que los efectos de una norma liberal no eran óbice para transformar las medievales convicciones sociales: La libertad es un estado, al igual que lo es la esclavitud. La libertad natural puede obtenerse sin estar en condición de acceder a la libertad social. En este caso, aunque se les dé el nombre de libres son de hecho esclavos. "[...] Para gozar la libertad social, entonces, no basta con un acto legislativo que los emancipe de la potestad de sus amos. [...]"27.

27 MOSQUERA, J. 1825. Memoria sobre la necesidad de reformar la ley del Congreso Constituyente de Colombia de 21 de julio de 1821, que sanciona la
Mosquera, hablando como un poderoso propietario, rechazó la Ley de vientres por considerarla adversa al derecho a la "propiedad privada": "Es un deber de la nación proteger por leyes sabias y equitativas la libertad, la seguridad, la propiedad y la igualdad de todos los colombianos" 28 , y aún cuando reconoció el esfuerzo de un gobierno libre no encontró razón para conceder la libertad a quienes él denominó como la "polilla de la sociedad" 29 , por cuanto entendió esta determinación como amenazante a las buenas y sanas costumbres de los hombres virtuosos de su tiempo. La propiedad privada junto con la libertad, la igualdad y la seguridad, fue uno de los primeros derechos civiles que protegió la constitución, entendiendo que los directamente implicados eran buenos ciudadanos que le aportaban sus impuestos al Estado.

\subsection{Determinantes y limitantes a la puesta en marcha de los derechos}

La declaración de libertad a los esclavos en Colombia fue una determinación rodeada de sectores a favor y en contra. Podría pensarse que los primeros beneficiados con la medida serían los mismos esclavos; sin embargo, en razón a las inexistentes políticas sociales que despejaran el camino para el desarrollo social que esta decisión demandaba resultaron mayormente beneficiados los propietarios y el mismo Estado.

\footnotetext{
libertad de los partos, manumisión y abolición del tráfico de esclavos y bases que podrían adoptarse para la reforma. Impreso por F. M. Stokes. Bogotá. [Localización: Archivo General de la Nación. Sección: Academia Colombiana de Historia. Colección de documentos varios. Caja 5, Carpeta 7]. En: RESTREPO, Eduardo. Argumentos abolicionistas en Colombia. História Unisinos no. 3. Vol. 10. Setembro/ dezembro de 2006. p. 303. Disponible en: www.ramwan.net

28 CONSTITUCIÓN POLÍTICA DE COLOMBIA DE 1821. Artículo 3. Disponible en: www. cervantesvirtual.com

29 MOSQUERA, J. 1825. Ob. Cit. p. 304.
} 
Cuando Don José Félix de Restrepo ${ }^{30}$ pronunció su discurso en Cúcuta, en el año de 1821, reservó un apartado específico a los esclavistas, en el les señalaba un horizonte económico próximo a las políticas del gobierno, y cómo éste les sería aún más benéfico a sus intereses particulares:

"Los economistas politicos calculan que el trabajo de un hombre robusto basta para mantener diez personas. Del mismo modo se puede conjeturar que un esclavo, que en su estado de tal trabaja como uno para su amo, siendo libre trabajará para sí, a lo menos como cinco. Por consiguiente, en el momento en que demos libertad a diez mil esclavos, aumentamos a la República cincuenta mil manos laboriosas [...] Como carecen de tierras y herramientas las arriendan o compran a sus amos, $y$ sirven en calidad de jornaleros por salarios moderados [...]"31.

Con un lenguaje moderno y liberal, Restrepo se refiere a la importancia y beneficio de la adopción de un sistema capitalista en el que el papel del propietario se funde en un "salario" y pueda recibir y exigir a cambio mayor y mejor producción, con menores inversiones en cuanto a cuidados y sostenimiento económico. Siguiendo la referencia de Restrepo a los propietarios de esclavos, más adelante precisa:

"[...] ya tenemos el costo anual de un esclavo en ochenta pesos. A precios más cómodos se encuentran en todas partes sirvientes libres. [...] Al hombre libre sólo se le ocupa en tiempo de arar, sembrar y cosechar; se le despide cuando no es útil, y nada se pierde en su muerte. [...] Sea pues que consultemos la razón o la experiencia, es imaginario el recelo de que faltando los esclavos

30 Jurista antioqueño que trabajó al lado de don Juan del Corral para proponer la Ley de Libertad de Partos. Restrepo se constituyó en la primera voz oficial a favor del fin de la esclavitud, sus propuestas acompañaron la historia jurídica de Colombia en esta materia, hasta la decisión final en 1851.

31 Félix de Restrepo, en su discurso presentado a los legisladores durante el Congreso de Cúcuta en 1821. Disponible en: www.utchvirtual.net no tendremos quien cultive la tierra y nos sirva en los ministerios domésticos ${ }^{\prime 32}$.

La positiva publicidad que Restrepo hacía a la adopción de un nuevo modelo económico guardaba directa relación con la necesidad política que tenía Colombia de recibir el reconocimiento y la validación de la comunidad internacional, donde el esclavismo y el feudalismo habían quedado atrás ya muchos años, y todo marchaba por la senda del capitalismo. En el año de 1823 del gobierno de Colombia recibió la visita del comisionado británico J. P. Hamilton, encargado de reportar a la Corona el estado en el cual se encontraba la república para hacer efectiva o no la vinculación de capitales ingleses a la economía:

"Debo informar a la Cámara que el Estado de Colombia ha hecho una ley para la extinción gradual de la esclavitud en todo su territorio; aqui no puedo menos que dirigirme al noble Conde que se halla al frente (el Secretario de Estado para las Colonias) y preguntarle isi un gobierno que ha hecho esto, no ha llevado al cabo una empresa harto dificil? Se han tomado medidas para dar a los esclavos regularmente su libertad; se ha establecido un impuesto para llevar a efecto su manumisión, y todos los hijos de las esclavas deben nacer libres. Es también debido al gobierno de Colombia el añadir, que esta gran medida se ha ejecutado de un modo satisfactorio tanto a los amos como a los esclavos. Se tuvo cuidado de asegurar a todas las partes una compensación por su pérdida. Tal estado de cosas no puede menos de ser satisfactorio a sus señorías" ${ }^{\text {"33. }}$

Con el informe de Hamilton se buscaba que los pactos de cooperación económica y comercial que los ingleses emprendieran con Colombia fueran efectivamente seguros y rentables. En la discusión que sobre el tema se llevó a cabo en

32 Ibídem.

33 En: CÁMARA DE LOS LORES. Londres, marzo 13 de 1824. Gaceta de Colombia No. 138. Bogotá. domingo 6 de junio de 1824. Intervención del Marqués de Lansdown. 
el Parlamento Británico, en la sesión del 3 de julio de 1823, ante la Cámara de los Comunes, Mr. Marryat se refirió a las ventajas de esta decisión:

"que el reconocimiento de la independencia de los Estados de la América del Sur por la Gran Bretaña daría un grande estímulo e incremento al comercio británico y que sostendría cualquiera moción que se hiciese con este objeto" ${ }^{\prime 34}$.

Otro aspecto significativamente validado por los ingleses tuvo que ver con el gobierno y el sistema político adoptado. Lo que podría tratarse aquí como una decisión exclusionista en materia de derechos políticos fue motivo de felicitación y reconocimiento por los lores, es decir, la limitación del derecho a la elección y participación política aseguraba la concentración del poder en manos preparadas lo que redundaba en firmeza y estabilidad para el gobierno:

"Cuando yo examino la constitución de Colombia hallo que contiene dos principios que sus señorías (los lores) no podrán menos que aprobar, a saber el dar influencia a la propiedad, y el asegurar los medios de educación. Las elecciones son conducidas de tal modo que impiden los males que nacen de una multitud de sufragantes sin propiedad. Cierta calificación de propiedad es también necesaria para dar el derecho de votar por los electores, $y$ otra mayor para los electores que eligen a los representantes" ${ }^{\prime 35}$.

Tanto las razones expuestas por Restrepo como las conclusiones presentadas por el comisionado británico James Hamilton, refieren que la manumisión de los esclavos fue una medida altamente benéfica y aprovechable para los propietarios de esclavos y para el Estado, queda por argumentar lo poco pertinente y positivo

34 Gaceta de Colombia No. 107. Bogotá, domingo 2 de noviembre de 1823

35 En: CÁMARA DE LOS LORES. Londres, marzo 13 de 1824 . Ob. Cit. que resultó para los actores principales del tema, los esclavos. Ciertamente, un acto legislativo no transforma de manera inmediata los comportamientos y las consideraciones de la sociedad, de hecho provocan reacciones inmediatas con implicaciones a corto y mediano plazo; este enunciado llevado al periodo de estudio establece que en efecto el panorama social no fue favorable a los esclavos. Existe una descripción realizada por Fray Gervasio García en el año de 1852 y lo que evidencia es el estado deprimente y deplorable en que aún permanecen no solo los esclavos sino también los libertos, a falta de políticas claras y definidas que enrumbaran el futuro de estos nuevos miembros de la sociedad:

"La unión conyugal entre los esclavos, hubo tiempo en que no la quisieron considerar como matrimonio, como si Jesucristo los hubiera excluido de la participación de este sacramento; pero el humilde y desgraciado fruto de esos enlaces, si lo consideraban sus amos como cosas de su pertenencia, he aqui el modo de confundir a esos infelices con las mismas bestias: es un ser a quien se mira con desprecio, condenado perpetuamente al trabajo como un bruto, con quien se puede traficar, sin que le sea permitido levantar la voz para reclamar los justos derechos de la naturaleza; es un infeliz que sin saber cómo ni por qué está abrumado bajo el enorme peso de una maldición lanzada por la sociedad; es un racional continuamente expuesto a la crueldad de su inhumano dueño, el que quizá convertido en su verdugo, le azota con mano de bronce y lo sepulta en una prisión, para que allí se consuma al rigor del hambre, de la sed y de la desnudez. Ved aquí lo que es un esclavo, y esto sin meter mano en multitud de iniquidades ocultas que solo Dios lo sabe"36.

36 GARCÍA, Fray J. 1852. Discurso que en acción de gracias por la completa libertad de esclavos en el territorio de la república de la Nueva Granda pronunció el R. P. Frai Jervasio García el $1^{\circ}$. de enero de 1852 en la villa de Zipaquirá. Imprenta de Torre Amaya por Carlos López. Bogotá. [localizado en la Biblioteca Nacional de Colombia. Fondo Antiguo, F. Vergara y Velasco, No. 13. p. 17.] 
El rechazo a la condición de esclavos y su propia alteridad racial y étnica impidieron en la población la observancia de la libertad como una decisión humanamente pertinente y propia de un Estado liberal. Cuatro años después de expedida la Ley de Partos, en 1821, el Senador Joaquín Mosquera ${ }^{37}$ hizo pública su posición en contra de la decisión de liberar a los esclavos por considerarla un atentado contra la paz y la seguridad de los "ciudadanos de bien":

"A mi me parece, que una multitud de tigres furiosos sueltos de la cadena, no harían tanto mal, como poner en ejercicio de sus fuerzas a estos hombres inmorales, sin honor, sin esperanza, sin temor. $\mathrm{La}$ nación se encontraría en el estado de anarquía salvaje, y tal vez sin medios para evitar los males que serian consiguientes al desenfreno de las pasiones brutales de estos monstruos, que celebrarían con horrible algazara su triunfo, sobre las ruinas de la libertad, y de la civilización" ${ }^{\prime 38}$.

\section{LOGROS CIVILES Y LOGROS POLÍTICOS}

Se conoce como "manumisión" al derecho que tuvieron los esclavizados en Colombia para recibir su libertad social y con ello su condición de autonomía; sin embargo, la manumisión tuvo varias limitantes, entres las que se encuentra el acceder a la libertad sin implicar la igualdad frente a sus libertadores, el formar parte de una nación sin acceder a la totalidad de sus derechos, por ejemplo, los políticos. Como ejercicio legal, la manumisión empezó a ser un derecho de naturaleza constitucional en el año de 1814 con la constitución de Antioquia, pero, evidentemente, durante la colonia se dieron varias resoluciones de "manumisión" guardándose su condición de particular y privada, es

\footnotetext{
37 La Familia Mosquera constituye un excelente ejemplo para mostrar la relación entre el carácter esclavista y político de los legisladores nacionales: durante el siglo XIX.

38 MOSQUERA, J. 1825. Ob. Cit.
}

decir, correspondiente a una juicio autónomo, individual y esporádico del amo que la otorgaba, bajo situaciones de reconocimiento a los servicios prestados, a la edad, a la enfermedad, o en poquísimas ocasiones a la compra de la libertad por parte de los esclavizados ${ }^{39}$.

Pese a las buenas intenciones, la manumisión no fue la solución a los problemas sociales de la república, como tampoco fue el estandarte de la libertad porque como medida jurídica estuvo sujeta a una serie de condiciones que limitaban las transformaciones a que apuntaba, también, porque esta determinación no tradujo proyectos políticos que la complementaran en su buen desarrollo, fue imprecisa y corta en contenido, y esa imprecisión terminó siendo una amenaza para buscar siempre la prolongación de la sujeción, bajo una esperanza de libertad que cada vez se hacía más lejana; por otra parte, el desempleo y la delincuencia no eran debidamente atacadas por los gobernantes pero sí se consideraba a los esclavos, libertos e indígenas como los protagonistas de estas acciones "pecaminosas" y "delincuenciales"

Haciendo parte del tratamiento pragmático y generalizado que se le trató de dar a algunos

39 En un importante documento que data del año 1803, se le concede la libertad a Hilario Franco, esclavo de Jacinta Monsalve, vecina del Valle de Ossos, la libertad es motivada por el Procurador General en razón a su avanzada edad y enfermedades. En: AHA. Índice: 1584 No. Orden: 00249 Fondo: Colonia Grupo: Negros y esclavos Sección: Antioquia Serie: Documentos Históricos Volumen: 4 Legajo: 34. Antioquia, 1803.

Juan Bautista Castro, presbítero, natural de Sevilla (España), otorgó libertad a sus esclavos Laura María Biáfara, a su hija Lucía y a Juan, hijo de la última, según voluntad testamentaria. En: AHA. Índice: 4 No. Orden: 0005 Fondo: Colonia Grupo: Negros y esclavos Sección: Antioquia Serie: Documentos Históricos Volumen: 1 Legajo: 1 Folios: 125 - 158. Antioquia, 1656.

40 Ver: HEERS, Jacques. Esclavos y sirvientes en las sociedades mediterráneas durante la Edad Media. Ediciones Alfonso el Magnánim. Valencia. 1989. 
derechos se puede afirmar que estas condiciones tuvieron una razón de conveniencia e inconveniencia según su grado de pertinencia. Por ejemplo, el derecho a la igualdad era en absoluto necesario y obligatorio cuando se trataba de participar en el ejército que protegería a la república de cualquier amenaza externa:

"todo ciudadano es soldado nato de la patria mientras que sea capaz de llevar las armas, sin distinción de clase, estado o condición [...]" ${ }^{\prime 41}$.

Ahora bien, el derecho a la igualdad traía consigo una serie de beneficios dado que la tendencia era hacer de los colombianos una nación homogénea. La idea de igualdad como asimilación fue un requisito para conceder las mercedes que el nuevo Estado liberal había fijado para los libertos; de hecho, así lo estableció la Ley de 3 de agosto de 1824, en su Artículo $4^{\circ}$ :

"de las tierras baldias que pertenecen a la República, distribuirá las fanegadas proporcionadas a cada una de las tribus indígenas gentiles que quieran abandonar su vida errante y se reduzcan a formas parroquiales, regidas y gobernadas en los términos está dispuesta para las demás de la República" y que "conforme a la Ley, hará que se provea de párrocos, sean seculares o regulares [...]" $]^{\prime 2}$.

La "civilización" como meta social equivalía a la superación del atraso y la miseria propia de los libertos; ella implicaba una condición de "blanqueamiento", es decir, la negación de su naturaleza humana y cultural, sólo así podían alcanzar la plenitud de los beneficios de un ciudadano activo, como los había llamado el

41 URIBE VARGAS, Diego. Las Constituciones de Colombia, Volumen II. Ediciones Cultura Hispánica. España. 1985.

42 Ley sobre los medios para civilizar a los indios salvajes. Agosto 3 de 1824. Artículos 1 y 3. En: LOPEZ DOMÍNGUEZ, Luis Horacio (Comp.). La obra educativa de Santander 1819 - 1826. Tomo I. Biblioteca de la presidencia de la República. Administración Virgilio Barco. Bogotá. 1990, p. 193.
Libertador $^{43}$. A falta de reconocimiento a la igualdad se les negó a los libertos el derecho político a la participación y a la representación, esto es, el impedimento a presentar desde sus propios intereses y conveniencias, planes y proyectos a su favor y lograr vincularlos a las tempranas agendas del Estado. Una curiosa situación fue que en Colombia se promulgó la libertad, se luchó por la libertad, se estableció constitucionalmente la libertad, pero no todos fueron libres; en palabras de Narváez Hernández "modernidad hipócrita de los Estados liberales" 44 . La Constitución de Cundinamarca -sancionada el 30 de marzo de 1812- establece un sistema excluyente frente al tema de los derechos políticos y electorales:

"para ser miembro de la representación nacional se requiere indispensablemente ser hombre de 25 años cumplidos, dueño de su libertad, que no tenga actualmente empeñada su persona por precio. [...] Ni serán admitidos en ellas [...] los vagos, ni los que hayan sufrido pena infamatoria, ni los que vivan a expensas de otros en calidad de sirvientes domésticos [...]"45.

Dos años antes a la sanción de la Constitución de Cundinamarca ya asomaban algunas contradicciones a las nuevas políticas democráticas, que finalmente no podían evitar llegar al mismo círculo de poder heredado de la colonia donde las minorías blancas negaban a las mayorías constituidas por negros, indios, mestizos, mulatos, etc. Así lo advirtió el Argos de la Nueva Granada para el año de 1810, enfatizando en el descontento por las medidas desvinculantes al acceso a la democracia generalizada y

43 Discurso pronunciado por Simón Bolívar el 15 de febrero de 1819, durante la instalación del Congreso de angostura. Disponible en: www.cervantesvirtual. com

44 NARVÁEZ HERNÁNDEZ, José Ramón. Ob. Cit. p. 42.

45 CONSTITUCIÓN DE CUNDINAMARCA DE 1812. Art. 14. Cap. IV. En: POMBO, Miguel Antonio, et al. Ob. Cit. 
acentuando en la necesidad de un modelo de gobierno abierto y participativo:

"Si los americanos quieren dar al mundo un testimonio de rectitud y justificación deberán determinar, que hasta el año de 1816 todo vecino de conocida honradez por miserable y pobre que sea, pueda elegir sus representantes y ser él mismo elegible" ${ }^{\prime 4}$.

En un tema tan trascendente como lo es el derecho político a la elección y a la representación, el historiador del derecho mexicano Javier Espinoza, incorpora un texto del diputado García Herreros, relacionado con el debate sobre la vinculación de los derechos a la constitución gaditana de 1812, y que no dista en nada de la decisión política adoptada en Colombia, incluso en 1821:

"Cualquiera que examine los derechos del hombre en sociedad no podrá menos de ver la inmensa distancia que hay entre los dos extremos propuestos, y que si bien todo ciudadano tiene derecho de ser protegido por las leyes, no todos son llamados al derecho de representación. La libertad civil, la propiedad de bienes, la seguridad personal, son derechos inseparables de todo ciudadano; pero iel entrar en la sociedad será bastante para elevarse al sublime cargo de legislador?" ${ }^{47}$

Finalmente, otro de los destacados alcances que tuvo la lenta y excluyente Ley de Partos fue el acceso a la educación, descrito constitucionalmente como la posibilidad de entrar en un programa de instrucción pública y gratuita ${ }^{48}$. Con las constituciones provinciales se ordenó la creación de escuelas de "primeras letras" y se

46 Continúa las reflexiones sobre nuestro Estado. En: Argos de la Nueva Granada. Santa fe, 5 de noviembre de 1810. p. 37.

47 ESPINOZA DE LOS MONTEROS, Javier, et al. Ob. Cit. p. 87.

48 CONSTITUCIÓN DEL SOCORRO. Artículo 6. CONSTITUCIÓN DE CUNDINAMARCA. Artículos 2 y 3. En: POMBO, Miguel Antonio, et al. Ob. Cit. le encargó la tarea a los religiosos y religiosas, principalmente. Por la Ley de "aprendizaje" expedida en 1839 puede deducirse dos aspectos de este derecho a la educación: el primero que no fue de general servicio a la población y muy probablemente los aún esclavizados no tuvieron posibilidades inmediatas de tal beneficio; el segundo, que la educación fundada en conocimientos en doctrina cristiana, obligaciones y derechos del ciudadano, geometría, ciencias naturales, agricultura y artes, no preparaba con suficiencia a este nuevo sector de la población en materia de trabajo libre y remunerado como lo había planteado el señor Restrepo en su Ley de Vientres del año 1814.

Lo fundamental en la educación tanto para negros como para indios era la "civilización", es decir el blanqueamiento cultural de estos dos grupos de actores, lo que se logró mediante la catequización y la conversión que impulsó la iglesia católica, la preparación en ciencias $\mathrm{y}$ artes no resultaba pertinente por cuanto el aprovechamiento que de ellos se esperaba estaba en el trabajo agrícola e industrial que se avecinaba. Como un caso excepcional la Gaceta de Colombia, número 121, registra una beca otorgada por el Presidente Francisco de Paula Santander, en el año 1824, a "Blas Torres, indigena descendiente de los caciques de Mamatoco, provincia de Santa Marta [...] en el Colegio Mayor del Rosario de esta capital, habiendo sido su padrino el excelentísimo señor vicepresidente de la República" 49 . Todo lo relativo a la educación de los indígenas fue entregada oficialmente a la Iglesia ${ }^{50}$ bajo la denominación de "civilización"

49 LÓPEZ DOMINGUEZ, Luis Horacio (Comp.). Ob. Cit. p. 153.

50 Como parte del proyecto educativo que lideró el General Santander durante su primer gobierno, en el año de 1821 expidió un decreto titulado "Los conventos se transforman en escuelas", con el fin de "promover la instrucción pública como uno de los medios más poderosos y seguros para consolidar la independencia". Los artículos 1 y 2 del decreto establecen la supresión de los conventos y su inmediata destinación para 
y como parte de la actividad misionera de los religiosos, de hecho, el $1^{\circ}$ de mayo de 1826, el mismo gobierno de Santander decretó la asignación anual de cien mil pesos para los gastos necesarios para esta labor ${ }^{51}$.

\section{CONCLUSIÓN}

Cuando terminó la independencia y se puso en pie la república, todas las promesas que se habían hecho acerca de la restauración de la dignidad humana de los neogranadinos debieron materializarse; los revolucionarios contenidos sociales expuestos en uno y otro discurso alcanzaron la prueba para su definitiva realización. Sin embargo, una vez autónomos, los miembros del gobierno debieron repensar todas las expresiones que lograron convocar las voluntades generales para enfilarse contra los españoles, y afloraron entonces una serie de situaciones que se mostraban poco propicias para el momento histórico. Los criollos americanos, herederos de los españoles, buscaron asegurarse como grupo de poder y las decisiones jurídicas que adoptaron estuvieron cercadas por intereses particulares tanto de tipo económico como político y social.

Establecida la república y con miras a la conformación de un cuerpo de nación, la constitución involucró una serie de derechos, tomados de los derechos del hombre y del ciudadano, cuyo fundamento liberal propendía por la protección de las libertades y las individualidades, pero con la tendencia a privilegiar aquellos que respondían de manera inmediata a las necesidades de su tiempo como la expresión, la propiedad, el ejercicio del comercio, la autonomía gubernativa, etc., de tal forma que la interpretación que se les daba dependía del interés y la pertinencia.

colegios, casas de educación y objetos de beneficencia pública. En: Archivo General de la Nación AGN. Sección: República Libros: Manuscritos Legajo: 20 Folios: 28-29.

51 Gaceta de Colombia No. 240. Bogotá. 1826.
La igualdad y la libertad, tan promulgadas desde la independencia, sufrieron el mismo tratamiento. Estos dos principios fundamentales y connaturales fueron mezquinamente entendidos y aplicados, con todo, de esta condición dependieron todos los demás derechos. Bajo la propuesta de manumisión se pretendió "elevar" a los esclavos a la par del resto de la sociedad, a la vez que las garantías constitucionales procuraron un carácter generalizador de sus disposiciones, pero en la práctica no fueron más que decisiones jurídicas de limitado impacto. La libertad de los naturales, interrumpida bruscamente por tres largos siglos de coloniaje, fue ahora un "permiso" para ser y para actuar; la igualdad un estado que debía alcanzarse mediante el sometimiento de la alteridad a la homogeneidad, en el caso concreto a la "aculturación", al "blanqueamiento".

Las denominadas minorías étnicas colombianas, conformadas originariamente por los indígenas y los negros africanos, quedaron inicialmente excluidas de la totalidad de los beneficios que tanto el liberalismo como la democracia habían establecido, la manumisión no logró ser la solución a los problemas sociales de su tiempo. Luego de tres décadas de repensar la posición de este sector de la población la influencia de los determinantes económicos y políticos fue superior, por lo que el acceso a los derechos civiles y políticos fue aplazado mientras la iglesia y el Estado les preparaban para su definitiva "inclusión".

\section{BIBLIOGRAFÍA}

\section{ARCHIVO HISTÓRICO DE ANTIOQUIA (AHA).
ARCHIVO GENERAL DE LA NACIÓN (AGN).

Argos de la Nueva Granada. Santa fe, 29 de octubre de 1810. 
Argos de la Nueva Granada. Santa fe, 8 de octubre de 1810 .

Argos de la Nueva Granada. Santa fe, 5 de noviembre de 1810 .

CÁMARA DE LOS LORES. Londres, marzo 13 de 1824. Gaceta de Colombia No. 138. Bogotá. domingo 6 de junio de 1824. Intervención del Marqués de Lansdown.

CASTRO, José Félix (Comp.). El Memorial de Agravios. Publicitaria. Bogotá. 1991.

"Código Negro". Disponible en: www.negrosyesclavos.archivogeneral.gov.co.

CONSTITUCIÓN POLÍTICA DE COLOMBIA DE 1821. Artículo 3. Disponible en: www. cervantesvirtual.com

Crónica de Caracas No.17. Marzo-Abril de 1954.

DE CERVANTES SAAVEDRA, Miguel. Don Quijote de la Mancha. Parte II. Capítulo LVIII. Disponible en: books.google.com.co

DE RESTREPO, Félix. Discurso presentado a los legisladores durante el Congreso de Cúcuta en 1821. Disponible en: www.utchvirtual.net

Decreto 22 de enero de 1820. Artículo 3. Disponible en: www.negrosyesclavos.archivogeneral. gov.co.

DICCIONARIO DE LA REAL ACADEMIA ESPAÑOLA. Vigésima segunda edición. 2001.

Discurso pronunciado por Simón Bolívar el 15 de febrero de 1819, durante la instalación del Congreso de angostura. Disponible en: www. cervantesvirtual.co

EL CONSTITUCIONAL. Bogotá, mayo 27 de 1821.

"E1 General Bolívar llama a las armas a 5000 esclavos y les ofrece la libertad. 1820". Disponible en: www.negrosyesclavos.archivogeneral. gov.co.
ESPINOZA DE LOS MONTEROS, Javier, et al. La noción de los Derechos en la historia del constitucionalismo mexicano. Suprema Corte de Justicia de la Nación. México. 2009.

Gaceta de Colombia No. 107. Bogotá, domingo 2 de noviembre de 1823 .

Gaceta de Colombia No. 138. Bogotá, domingo 6 de junio de 1824.

Gaceta de Colombia No. 240. Bogotá. 1826.

GARCÍA, Fray J. 1852. Discurso que en acción de gracias por la completa libertad de esclavos en el territorio de la república de la Nueva Granda pronunció el R. P. Frai Jervasio García el $1^{\circ}$. de enero de 1852 en la villa de Zipaquirá. Imprenta de Torre Amaya por Carlos López. Bogotá. [Localizado en la Biblioteca Nacional de Colombia. Fondo Antiguo, F Vergara y Velasco, No. 13. p. 17.]

GARRIDO, Margarita. Reclamos y representaciones: Variaciones sobre la politica en la Nueva Granada. 1780 - 1815. Banco de la República. Bogotá. 1993.

HEERS, Jacques. Esclavos y sirvientes en las sociedades mediterráneas durante la Edad Media. Ediciones Alfonso el Magnánim. Valencia. 1989.

LA BAGATELA. Santa Fe, Domingo 2 de diciembre de 1811 .

LÓPEZ DOMÍNGUEZ, Luis Horacio (Comp.). La obra educativa de Santander 1819 1826. Tomo I. Biblioteca de la presidencia de la República. Administración Virgilio Barco. Bogotá. 1990.

MEJÍA QUINTANA, Oscar, et al. Cultura $y$ Democracia en América Latina. Elementos para una reinterpretación de la cultura y la historia latinoamericana. M\&T. Bogotá. 1992.

MOSQUERA, J. 1825. Memoria sobre la necesidad de reformar la ley del Congreso 
Constituyente de Colombia de 21 de julio de 1821, que sanciona la libertad de los partos, manumisión y abolición del tráfico de esclavos y bases que podrían adoptarse para la reforma. Impreso por F. M. Stokes. Bogotá. [Localización: Archivo General de la Nación. Sección: Academia Colombiana de Historia. Colección de documentos varios. Caja 5, Carpeta 7]. Nariño, Antonio. "Pluris nubius". En: La Bagatela. Santa Fe. Domingo 2 de diciembre de 1811.

NARVÁEZ HERNÁNDEZ, José Ramón. Historia social del Derecho y la Justicia. Editorial Porrúa. México. 2007.
POMBO, Miguel Antonio, et al. Constituciones de Colombia. T.I. Biblioteca Banco Popular. Vol. 127. Bogotá. 1986.

RESTREPO, Eduardo. Argumentos abolicionistas en Colombia. História Unisinos no. 3. Vol. 10. Setembro/dezembro de 2006. p. 303. Disponible en: www.ram-wan.net

URIBE VARGAS, Diego. Las Constituciones de Colombia, Volumen II. Ediciones Cultura Hispánica. España. 1985. 